\title{
САМОРАЗВИТИЕ РЕБЕНКА В СЕМЬЕ
}

\section{SELF-DEVELOPMENT OF A CHILD IN THE FAMILY}

M. Zemsh

Summary: This article examines the role of the child, the article summarizes the experience of family education in the era of the Russian Empire and analyzes the experience of the modern family, analyzes the causes and factors that hinder the process of self-development of children in the family, examines the importance of the social status of the family, which, due to the lack of compulsory preschool education, should prepare the child for entering the collective school life, adapt it to the environment.

The author draws attention to the fact that with all the variety of pedagogical studies devoted to the study of the importance of the family in the formation of the child's self, modern pedagogical theory shows an underestimation of the domestic experience of implementing the educational potential of the family as a socio-cultural system that affects the formation of the worldview and worldview of a growing personality. The article presents an analysis of pedagogical researchers on the problem of child self-development in the family. The author examines the issues of the educational role that exist in modern families, describes the concept of educational opportunities for family education and provides conditions that affect this process.

The author of the article notes that the modern family plays a primary role in the creative and cognitive self-development of children. The main task in this process should be to create conditions that maximize the growth and self-development of the child's personality. This process will be more effective if we can understand the experience of successful socio-cultural education on the example of the Russian nobility, which makes it possible to model models of modern family educational systems that combine the experience of past generations and modern educational technologies.

Keywords: family, upbringing, self-development, personality, factors, success, influence, parents, environment, education, conditions.

\author{
Земи Марина Борисовна \\ К.п.н., доцент, Государственный \\ гуманитарно-технологический университет, \\ mz-ped@mail.ru
}

Аннотация: В данной статье рассмтаривается роль семьи в процессе самореализации ребенка, обобщается опыт семейного воспитания в эпоху Российской Империи и анализируется опыт современной семьи, анализируются причины и факторы, мешающие процессу саморазвития детей в семье, изучается важность социального статуса семьи, которая из-за отсутствия обязательного дошкольного образования должна подготовить ребенка к поступлению в коллективную школьную жизнь, адаптировать его к окружению. Автор обращает внимание на тот факт, что при всем многообразии педагогических исследований, посвященных изучению значения семьи в формировании самости ребенка, в современной педагогической теории наблюдается недооценка отечественного опыта реализации воспитательного потенциала семьи как социокультурной системы, влияющей на становление мировосприятия и миропонимания растущей личности. В статье приведен анализ педагогических исследователей на проблему саморазвития ребенка в семье. Автором рассматриваются вопросы воспитательной роли, существующие в современных семьях, охарактеризовано понятие воспитательных возможностей семейного воспитания и приводятся условия, которые воздействуют на этот процесс.

Автор статьи отмечает, что современная семья играет первостепенную роль в творческом и познавательном саморазвитии детей. Главной задачей в этом процессе должно стать создание условий, максимально способствующих росту и саморазвитию личности ребенка. Этот процесс станет эффективнее, если удастся осмыслить опыт успешного социокультурного воспитания на примере русского дворянства, что дает возможность моделировать модели современных семейных воспитательных систем, соединяющих в себе опыт прошлых поколений и современные воспитательные технологии.

Ключевые слова: семья, воспитание, саморазвитие, личность, влияние, среда, условия.

Между семьей и детьми существует невидимая прочная связь. В раннем детстве и, даже в юношеском возрасте, дети копируют поведение родных. Еще не понимая и не осознавая многих поступков, маленький ребенок неосознанно стремится быть похожим на своих родных, подражая и копируя их поведение, которые на подсознательном уровне остаются в его памяти, формируя мировоззрение, на взгляды которого он будет ориентироваться и во взрослой жизни [3].

Влияние семейного воспитания на формирование детской личности сильнее других воспитательных воздействий, которые он получает в саду, школе, на улице [2]. Конечно, с течением времени и при взрослении 
ребенка это воздействие становится слабее, однако полностью никогда не утрачивается. Семья закладывает в детскую личность те качества, которые не могут быть сформированы больше нигде и никем. К таким качествам также относится уровень образованности и воспитанности детей [1].

При этом стоит отметить, что несколько лет назад не было столь актуальным исследование воспитательного влияния семьи на развитие будущей личности. Это вопрос стал на современном этапе объектом многих общественных и научных дискуссий [1]. Многие выводы современных исследований являются настолько пессимистичными, что становится очевидным тот факт, что традиционной семье все больше необходима психолого-педагогическая помощь.

\section{Шели статьи}

Целью исследования, представленного в статье, является обзор отечественного опыта семейного воспитания в дворянских семьях в историко-культурном и педагогическом аспектах. Исследование направлено на выявление социо-культурных элементов организации семейной воспитательной системы, воздействующих на процесс саморазвития растущей личности, а также анализ значимости социального статуса современной семьи, призванной обеспечить адаптацию растущей личности к условиям динамичной социальной среды.

Актуальность исследования заключается, прежде всего, в том, что при всем многообразии педагогических исследований, посвященных изучению значения семьи в формировании самости ребенка, в современной педагогической теории наблюдается недооценка отечественного опыта реализации воспитательного потенциала семьи как социокультурной системы, влияющей на становление мировосприятия и миропонимания растущей личности.

\section{Из^ожение основного материала статьи}

Глобальные изменения развития мирового сообщества влечет за собой сдвиг морально-нравственных, национальных, образовательных ценностей во всех уголках мира. Гуманистические ценности и идеалы свободы выбора личностью индивидуального пути саморазвития и своей жизни декларируются в качестве доминант при организации современных правовых, дипломатических и даже экономических отношений на внутригосударственном и межгосударственном уровнях.

Современное образовательное пространство строится в условиях единой системы, в процессе чего происходит модернизация и отечественного образования. Формирование и внедрение новых государственных образовательных стандартов касается не только самого образования, но и воспитания в целом [7].

В историко-педагогических исследованиях советского периода под влиянием марксистско-ленинской теории вопросы освещения отечественного опыта семейного воспитания были существенно идеологизированы [2]. Это привело к тому, что в советской педагогике интерес к вопросу о воспитании детей в семьях эпохи Российской Империи был утрачен. Однако изучение взглядов на воспитание в дворянских семьях возобновилось в постсоветский период, и сегодня относится к числу фундаментальных направлений историко-педагогических исследований, позволяющих обосновать предпосылки развития социокультурной парадигмы семейного воспитания.

Неоспоримым является тот факт, что дворянина считали не только человеком, имеющего понятие чести и достоинства, но он обладал качествами безупречного хозяина: был бережлив, скромен, трудолюбив, образован, учтив, воспитан [2, с. 8-13]. Именно для дворянства были присущи качества собственного достоинства, чести, нравственности. Эти качества специально закладывались в сознание растущей личности с самого детства, параллельно с нравами обыденной жизни. Чтобы ребенку с самого детства были знакомы и приняты им нравственные ценности окружающего общества, чтобы он соблюдал установленные традиции и порядки, ему необходимо было эти знания прививать с самого раннего возраста на протяжении продолжительного времени. Этим занимались гувернеры, которых специально приглашали в дворянские семьи. С французского языка «гувернер» означает «воспитатель детей, приглашаемый в буржуазные семьи» [2].

В эпоху правления Екатерины такая система образования получила широкое распространение. В этот период идет активное переселение иностранцев из Европы В Россию. В результате почти все дворянские семьи имеют гувернеров, в основном немцев и французов. Эти иностранцы могли обучать дворянских детей правилам этикета, вежливости, нравственности. Также, в круг их функций входило обучение танцам, пению, музыке, чтению литературы, письму, грамоте, иностранным языкам [5]..

Практика воспитания и обучения под наблюдением специального наставника обладала, кроме всего прочего, еще несколькими преимуществами: все время ребенка контролировалось его учителем, нравственными пояснениями и воспитанием в любое время дня. Свободное время ребенок проводил за чтением книг, танцами и музыкой. Именно это метод в обучении и воспитании детей дал возможность индивидуального подхода к каждому ребенку. 
Отметим, что воспитанники семей тех времен уже в раннем юношеском возрасте могли свободно общаться на двух и более иностранных языках, играли на нескольких музыкальных инструментах, в том числе и на фортепиано, хорошо разбирались в искусстве и литературе, владели знаниями в военном деле.

Представители той эпохи смогли не только перенять европейский опыт семейного воспитания, но и сохранить свою национальную самобытность, не потерять национальное самосознание. Воспитание будущих поколений в российских семьях сочетало в себе нравственные, духовные, интеллектуальные условия развития личности ребенка.

При царствовании Анны Иоанновны деятельность гувернеров попала под усиленный контроль, функции которого возлагали на Греко-латинскую Академию. Только с ее позволения в семье разрешалось держать гувернера, при этом, владеющего греческим, латинским языком под страхом конфискации имущества [2, с. 60].

Этот факт способствовал тому, что в государстве образование и воспитание в семье отошло от европейских ценностей и стандартов, а качество семейного воспитания вышло на новый качественный уровень. На этом этапе система образования в России выстраивалась по принципу взаимодействия: русская самобытность + гувернѐр + религия (преимущественно православие).

Такое взаимодействие дало возможность воспитывать развитую, с привитыми духовно-нравственными ценностями личность, которая была способна к адаптации в любом обществе, что предполагало распространение зарубежных форм воспитания и образования[5]. В этот же момент, православие занимало важное место в содержании и организации семейного воспитания, что способствовало укреплению в мировоззрении подрастающего поколения чувства национальной идентичности.

Таким образом, как показал исторический опыт, среда семейного воспитания, основанная на соединении передовых зарубежных практик и глубоко воспринимаемых растущей личностью национальных традициях, является примером успешной модели взращивания социально активной личности с высокоразвитыми нравственными качествами, способной к адаптации в социокультурной среде и творческому ее преобразованию.

В современном обществе отмечается наличие двух крайностей в семейном воспитании: педагогически запущенные дети и дети, с которыми родители занимаются с самого рождения. При это роль семьи в саморазвитии растущей личности трудно переоценить.
Очевидно, что процесс саморазвития успешнее происходит в семейной обстановке, когда ребенок начинает проявлять интерес к какой-нибудь творческой деятельности взрослого члена семьи, например, к рисованию или музыке [10]. Одаренные от природы дети лучше воспринимают гармонию и красоту в природе, что дает им возможность иногда раскрыться быстрее и лучше. Однако и в этом случае саморазвитие ребенка должно контролироваться родителями, которые будут направлять, и регулировать необходимую информацию для этого развития и для самореализации в обществе в целом[12].

Для саморазвития ребенка в современной семье стоит уделять внимание в первую очередь правильной организации семейного досуга. К ней можно отнести, например: чтение литературы, разгадывание кроссвордов, просмотр разно жанровых фильмов и обсуждение их сюжета, совместный отдых с родственниками, друзьями, посещение театров, музеев; посещение парков, экскурсии, прогулки на природу; занятия спортом, участие в соревнованиях, в проведении праздников [5].

Все эти занятия помогают ребенку раскрыть многообразие окружающего мира, увидеть различие между людьми и их образом жизни. Дети узнают много нового и полезного. У них появляется интерес к познанию еще чего-нибудь нового, пропадает желание остановиться на достигнутых знаниях, их ум постоянно ищет интересное занятие, помогая проявиться и найти реализацию различным личностным способностям и талантам. Все это способствует расширению кругозора детей. А родители могут сделать так, чтобы этот интерес был устойчивым и не угасал с возрастом.

Последние исследования содержат, к сожалению, факты неспособности современных родителей в полной мере обеспечить духовное развитие своих детей [10]. На первый план выходит обеспечение материальнотехнического характера, забывая о важности и первоочередности морально-духовных ценностей. Семейный досуг, в особенности в условиях пандемии, практически не содержит таких форм как совместный поход в театр, музей, церковь; все чаще семья выбирает теле-развлекательные средства, чем разговор в теплой семейной обстановке, результатом чего является резкое снижение воспитательного духовного потенциала семьи.

Современная жизнь очень стремительна и, часто родителям легче сделать и решить все за ребенка самостоятельно (собрать игрушки, застегнуть пуговицу), лишая его проявления инициативы, развития самостоятельности и уверенности в своих поступках. Научить ребенка многим действиям требует времени и терпения, которых часто не хватает родителям. Нехватка времени, опасения за жизнь или здоровье своего ребенка, гиперосторожность родителей приводит к тому, что при посещении 
детского сада ребенок не приучен к самостоятельности, и желание его научиться чему-нибудь пресекается такими запретами, как, например «Ты не умеешь», «Я сделаю быстрее, не трогай». В дальнейшем эти дети становятся неуверенными, нерешительными как в дошкольном, так и в школьном детстве. В этом случае родители, не понимая сами, сдерживают саморазвитие и познавательную мотивацию у своих детей.

\section{Выводы}

В заключении хотелось бы отметить, что родителям необходимо помнить о том, что детям просто необходимо создавать такую среду, в которой ребенок смог бы чувствовать себя комфортно не только физиологически, но и психологически [14]. Необходимо помогать ему развивать свои потенциальные таланты, не перегружая детскую психику стремлениями сделать из него вундеркинда. Ребенок, который мотивирован своими родителями, который стремится к познанию, сможет добиться высоких результатов в саморазвитии и образовании.

Стремясь дать лучшее образование и развитие своим детям, родителям стоит уделять внимание развитию всех его качеств и черт: художественных, морально-эстетических, нравственных, эмоциональных, творческих и социальных. Наличие благоприятной атмосферы, ранее приобщение ребенка к труду, чтению, самообслуживанию, культуре и привитию национальных, моральнонравственных ценностей и является залогом успеха воспитания и саморазвития детей в семье.

Ребенок, имеющий высокие способности, но, не мотивируемый своими родителями к познанию и саморазвитию, растет в страхе за непослушание, за плохой результат в какой-то выбранной ими деятельности очень часто не проявляет себя во взрослой жизни, когда авторитет родителей уже не имеет подавляющего влияния, а интерес к саморазвитию так и не привит ребенку родителями в детстве.

Современной семье отводится особая роль в творческом и познавательном саморазвитии детей. Главной задачей в этом процессе должно стать создание условий, максимально способствующих росту и саморазвитию личности ребенка. Этот процесс станет эффективнее, если удастся осмыслить опыт успешного социокультурного воспитания в семьях русской культурной элиты, что дает возможность выстаивать эффективные модели современных семейных воспитательных систем, соединяющих в себе опыт прошлых поколений и современные воспитательные технологии.

\section{ЛИТЕРАТУРА}

1. Агарагимова В.К. Актуальные проблемы семейной педагогики в контексте современных социокультурных реалий // Научные исследования и образование. -2016 . - № 3(23). - с. 79-82.

2. Акимова Е.А. Духовно-нравственные традиции воспитания в русской семье // Наука и технологии в современном обществе. - 2016. - № 1 - с. 21-25.

3. Амонашвили, Ш.А. Основы гуманной педагогики. Книга 8. Искусство семейного воспитания / Ш.А. Амонашвили. - М.: Амрита-Русь, 2017. - 952 с.

4. Бочарова Н.И. Педагогика досуга. Организация досуга детей в семье: учеб. пособие для академического бакалавриата / Н.И. Бочарова, 0.Г. Тихонова. 2-е изд., испр. и доп. - М.: Издательство Юрайт, 2019. - 218 с.

5. Измайлова А.Б. Традиция русской народной педагогики в современном семейном воспитании. Современные проблемы психологии и образования в контексте работы с различными категориями детей и молодежи: материалы II Всерос. с междунар. участием науч.-практ. конф., Москва, 26-27 апр. 2018 г. - Москва, 2018. - с. 315-320.

6. Мартынова 0.В. Семья и ее роль в воспитании личности дошкольников. Методы партнерского взаимодействия детского сада с родителями / 0.В. Мартынова. - Текст: непосредственный // Молодой ученый. - 2019. - № 27 (265) - с. 266-268.

7. Михащенко А.Л. Современное состояние семейной педагогики. Педагогическая мысль о семейном воспитании в Российской Федерации. Семейная педагогика: антология педагогической мысли: учеб пособие / А.Л. Михащенко. - Курган: 2011. - с.162-180.

8. Островская Л.Ф. Педагогические ситуации в семейном воспитании дошкольников / Л.Ф. Островская. - М.: Просвещение, 2020. - 160 с.

9. Селезнева Е.В. Саморазвитие личности как акмеологическая категория // Акмеология - 2002.- №1-с. 18-25

10. Сергеева, В.П. Основы семейного воспитания. Учебник для студентов учреждений среднего профессионального образования / В.П. Сергеева. - М.: Академия (Academia), 2019. - 698 с.

11. Сорокоумова Е.А. Психология детей младшего школьного возраста. Самопознание в процессе обучения: учеб. пособие для СПо / Е.А. Сорокоумова. - М.: Издательство Юрайт, 2019. - 216 с.

12. Хухлаева О.В. Психология развития и возрастная психология: учебник для СПО / О.В. Хухлаева, Е.В. Зыков, Г.В. Базаева; под ред. О.В. Хухлаевой. - М.: Издательство Юрайт, 2019. - 367 с.

13. Щукина М.А. Саморазвитие личности сквозь призму антропологизма // Вестник УДК 159.9.01 СПбГУ. Сер. 12. 2011.

14. Lesgaft P.F. Family upbringing of a child and its significance / P.F. Lesgaft. - Moscow: KD Librokom, 2019. - 216 p.

15. Pere B. The first three years of a child's life: Etude of experimental psychology. With the Appendix of the article by A. Ben «Education as a science». Per. with FR. / B. Peer. - M.: CD Librocom, 2019. - 320 p. 
16. Gritsay L.A. Family pedagogy: the history of family education: textbook. manual / L.A. Gritsay. - Saratov: Al PI er Media, 2019. - 154 p.

17. Jafarova D.T. Study of the problem of family education in modern pedagogical research / / World of science, culture, education. - 2016. - № 4 (59). - Pp. 134-136.

18. Carol A.D. Family Life Education: Working with Families across the Lifespan. - Third Edition. - Long Grove, Illinois: Waveland Press, Inc., [2014]. - 403 p.

19. Ryder V. Parents and their children / Verdene Ryder, Celia A. Decker. - Tinley Park, Illinois: Goodheart-Willcox Company, Inc., [2015]. - 624 p.

20. Steinberg L.D. You and your adolescent: the essential guide for ages 10-25. - New York: Simon \& Schuster, 2011. - 415 p.

(c) Земш Марина Борисовна (mz-ped@mail.ru).

Журнал «Современная наука: актуальные проблемы теории и практики»

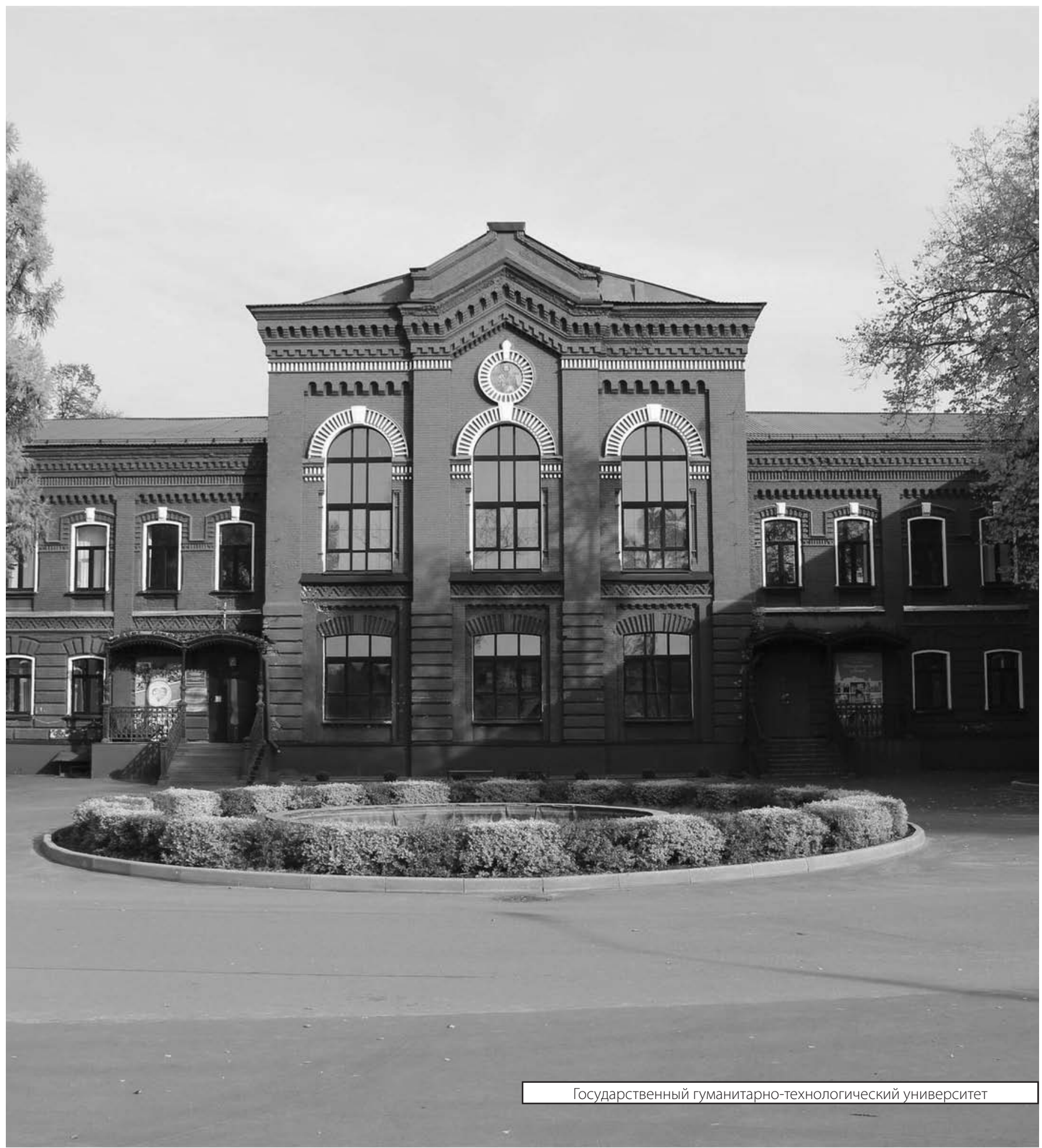

